\title{
ASPECTOS HISTÓRICOS DA CRIAÇÃO DA ESCOLA COMUNITÁRIA CASA FAMILIAR RURAL DE BELTERRA
}

\author{
Poliana Fernandes Sena e Sousa \\ Universidade Federal do Oeste do Pará (UFOPA) \\ poliana.sena@ufopa.edu.br \\ Solange Helena Ximenes Rocha \\ Universidade Federal do Oeste do Pará (UFOPA) \\ solange.ximenes@gmail.com
}

\section{RESUMO}

Este artigo traz elementos históricos sobre a criação da Escola Comunitária Casa Familiar Rural de Belterra que adota a Pedagogia da Alternância como proposta metodológica. Tais elementos partem de uma pesquisa de campo que teve como objetivo analisar a implantação da experiência da Pedagogia da Alternância na referida escola. Os sujeitos são alternantes, pais de alternantes, monitores e a presidente da associação da Escola Comunitária Casa Familiar Rural de Belterra. Foi possível constatar fortalecimento das unidades produtivas através da formação técnica e de acesso as políticas públicas para agricultura familiar; necessidade de superar problemas de infraestrutura no prédio da escola e no alojamento dos alternantes; e reorganização do currículo que privilegia a formação técnica em detrimento da formação geral. Em que pese a importância da experiência, as respostas que tem dado aos anseios da comunidade em superar as carências educacionais do município de Belterra e o enfrentamento à expansão do agronegócio e a monocultura da soja na região, entende-se, assim como Bezerra Neto (2003) que a esta não pode ser atribuído papel de redentora das problemáticas educacionais do município e que sozinha não dá conta de melhorar a vida dos sujeitos.

Palavras Chaves: Pedagogia da Alternância; Casa Familiar Rural; Formação Técnica.

\section{HISTORICAL ASPECTS OF THE CREATION OF THE COMMUNITARIAN SCHOOL RURAL FAMILY HOUSE FROM BELTERRA}

\section{ABSTRACT}

This paper brings historical elements concerning the creation of the communitarian School Rural Family House from Belterra which adopts the Pedagogy of Alternation as a methodological proposition .Such elements come from a field research that aimed to analyze the implantation of the experience regarding the Pedagogy of Alternation at the mentioned school. The subjects are students, monitors, students' parents and the president of Association of the communitarian School Rural Family House from Belterra. It was possible to determine the strength of the productive units through technical training and access to public policies concerning the familiar agriculture. The need to overcome infrastructure problems at the school building and at the students' dormitory; and reorganization of the curriculum which grants a privilege to technical training over general education. In spite of the importance of the experience, the answers that have been pleased the community desires concerning the overcoming of educational scarceness of Belterra town, the coping to the expansion of soya agrobusiness and monoculture in the region, it is comprehended, like Bezerra Neto (2003) that to this one cannot be assigned the redemptive role regarding the educational problems of the city and it cannot handle the subjects' life improvement by itself.

Keywords: Pedagogy of Alternation; Rural Family House; Technical training. 


\section{Introdução}

Há um significativo incremento de pesquisas na área da educação que tomam a região amazônica como espaço de estudo. A ampliação da qualificação de docentes vinculados a educação básica e superior na região, a criação de novos programas de pósgraduação stricto sensu, a análise crítica dos diferentes projetos implantados na região são alguns dos elementos que ajudam a explicar este fenômeno. Este estudo, vinculado ao Programa de Pós-graduação em Educação da Universidade Federal do Oeste do Pará se insere neste contexto e objetiva relatar a história da criação da Escola Comunitária Casa Familiar Rural de Belterra que tem como proposta pedagógica a Pedagogia da Alternância.

A pedagogia da Alternância é uma metodologia nascida no meio rural, mas que o transcende, uma vez que se compreende que toda relação pedagógica é uma dialética integradora entre o saber escolar e os saberes da vida. De acordo com Ribeiro (2003, p. 142) "é a vinculação entre o meio escolar e o meio familiar-comunitário. Esse sistema deve permitir aos jovens frequentar a escola sem prejudicar ou inviabilizar a produção realizada através de laços e braços da família”.

A proposta da Pedagogia da Alternância tem a sustentação legal na Lei de Diretrizes e Bases da Educação Nacional (9394/96), no artigo 23 e seus respectivos incisos, apoiados também nos artigos 28 e 34 da referida legislação e no Parecer CNE/ CEB 1/2006, aprovado em 01/02/2006 que trata sobre aprovação dos dias letivos para a aplicação da Pedagogia da Alternância nos Centros Familiares de Formação por Alternância (CEFFA).

Entre as diversas propostas que adotam a Pedagogia da Alternância no Brasil, está a Escola Comunitária Casa Familiar Rural de Belterra - ECCFRB que é a mais recente experiência sob a perspectiva da alternância implantada no Estado do Pará. Isto posto, para compreender a implantação da ECCFRB faz-se necessário retomar a história da criação do município de Belterra, bem como, o momento anterior de implantação do empreendimento fordista na região amazônica.

\section{Do empreendimento Fordista à cultura da Soja}

O empreendimento Fordista se instalou na Amazônia na década de 1920 quando havia uma demanda mundial por látex, matéria prima responsável pela produção de borracha, insumo utilizado na produção de automóveis, uma vez que o setor automobilístico estava em alta. De acordo com Pereira (2012, p.55), "o interesse do capital americano na região do Tapajós no final de 1920 envolveu questões econômicas e políticas de múltiplas determinações e diversas escalas de articulação entre o capital internacional, governo brasileiro e oligarquia na Amazônia".

A Amazônia vivia em um período de estagnação econômica no pós boom da borracha ${ }^{1}$. Como consequência, houve a perda de renda dos estados produtores de seringa, como também da oferta de postos de trabalho, precarização da qualidade de vida dos migrantes (antigos seringueiros), além da fragilização política das oligarquias locais no cenário nacional, pois não havia mais dinheiro, as oligarquias, sobretudo, de Manaus e Belém estavam em decadência (PEREIRA, 2012).

O governo brasileiro favoreceu a implementação de capital americano na região Amazônica, através da CFIB (Companhia Ford Industrial do Brasil), concedendo benefícios fiscais, conferindo total autonomia para a utilização dos recursos existentes na região por um período de 50 anos. Essa concessão gerou instabilidade no governo, pois se 
cogitou a venda do Estado do Pará aos americanos, esse fato suscitou diversas críticas ao governo estadual.

Data de 1928 a chegada da CFIB em Fordlândia, atual distrito do município de Aveiro. Dois navios americanos trouxeram máquinas e os equipamentos para construção da cidade-empresa que daria apoio para a atividade de exploração da seringueira na região do rio Tapajós. Segundo noticiou o jornal The New York Times, em 26 de julho de 1927, o navio Lake Ormoc partiu de Detroit com destino à Santarém, no Brasil, para abastecer de suprimentos, máquinas, pessoal e equipamentos o seringal de Henry Ford na Amazônia. Hospitais, oficinas, casas, escolas, cinemas, estradas, serraria, depósitos, restaurantes, campo de futebol, igreja, sistema de abastecimento de água e energia, ferrovia, entre outros foram instalados na região (PEREIRA, 2012).

Segundo Sena (2008, p.93), "Fordlândia seria a primeira "cidade empresa" na Amazônia criada para garantir a lógica dos grandes projetos, provocando verdadeira revolução na realidade local e regional, transformando as relações de trabalho e a vida dos habitantes". O investimento feito em Fordlândia estava orçado em cerca de 20 milhões de dólares, tal montante, no entanto, não foi suficiente para que o empreendimento obtivesse sucesso. De acordo com Sena (2008), a topografia montanhosa, o solo arenoso, o elevado custo de implantação do seringal, o clima com elevada umidade relativa do ar propiciou a proliferação do maior inimigo das seringueiras na Amazônia, o "Mal das Folhas", causado pelo fungo Microcyclus.

O fracasso vivenciado em Fordlândia provocou o deslocamento do projeto para Belterra. A CFIB realizou então a plantação em áreas mais planas, consideradas apropriadas para o plantio, importou um novo tipo de seringueira mais resistente e usou enxerto nas mudas para torná-las mais resistentes às pragas.

Assim como em Fordlândia, em Belterra foi erguida uma grande infraestrutura para dar suporte à Companhia, tais como: construção de portos, galpões, arruamento e sistema de iluminação, sistema de abastecimento de água, telefonia, creche, escola, escritórios, alojamentos, hospital, cadeia, igrejas, bosques, campo de aviação, clube de golfe, praças e casas para as diferentes categorias de trabalhadores da CFIB. Vale ressaltar que existia uma clara divisão entre os trabalhadores, inclusive na nomenclatura das vilas: os trabalhadores estrangeiros habitavam a vila americana e os demais habitavam a vila operária.

A imponente infraestrutura e a visibilidade dada ao projeto, favoreceram a viagem a Belterra do então presidente da república Getúlio Vargas. A visita tinha como pano de fundo a aliança entre os Estados Unidos e o governo brasileiro, além da "Marcha para o Oeste", que, dentre outros, objetivava povoar o território amazônico, por isso a justificativa de incentivos fiscais ao empreendimento de Henry Ford. Segundo Pereira (2012, p.107):

A visita do presidente Getúlio Vargas à Belterra não foi um ato formal descompromissado. Lembramos da disputa no mercado internacional entre as grandes potências mundiais em torno da produção da borracha em larga escala, especialmente do conflito envolvendo Japão e Estados Unidos na II Guerra Mundial, das possibilidades abertas para as relações comerciais e políticas entre EUA e governo brasileiro e das negociações que envolveram a Amazônia.

Os acordos assinados entre Brasil e Estados Unidos durante a II Guerra Mundial, em 1942, tanto situaram o Brasil no conflito, como lhe deram o papel de principal fornecedor de borracha para abastecer o mercado americano, especialmente aquele ligado à indústria armamentista. Chamar mão de obra para os seringais e abastecer com borracha os 
aliados foi a incumbência brasileira naquele contexto de guerra. Nessa perspectiva, os "soldados da borracha", como foram conhecidos os trabalhadores arregimentados, constituíram a força de trabalho estratégica para dar conta daquela missão que o Brasil havia recebido (PEREIRA, 2012).

O governo Roosevelt assinou acordos com países latino americanos para a produção da borracha durante a guerra. Por sua vez, Getúlio Vargas assumiu o compromisso de abastecer o mercado americano até 1946, em troca de um empréstimo de US\$ 100 milhões, cujo acordo de cooperação incluía o trabalho em conjunto com organizações americanas. É importante lembrar que nesse período a Ford Company Motors nos Estados Unidos suspendeu por cerca de três anos a produção de veículos civis para produzir jipes, aviões e tanques para as forças militares daquele país para atuarem na guerra. Neste "esforço de guerra", as plantações de seringas da CFIB na Amazônia desempenhavam seu papel estratégico (GRANDIN, 2010).

A CFIB permaneceu na região do Tapajós por dezoito anos, de 1928-1945. O pano de fundo da interrupção do projeto foi o final da segunda guerra mundial, a queda da demanda por borracha e, além disso, a produção da borracha sintética que substituía em grande parte a borracha natural. Os Estados Unidos e Inglaterra passaram a ser parceiros, o que fez com que os ingleses derrocassem o cartel da borracha produzida no sudeste asiático (SENA, 2008).

Com a saída da CFIB de Belterra, em 1945, toda infraestrutura e benfeitorias construídas pelos americanos foram repassadas ao governo brasileiro pelo valor de pouco mais de US\$ 240 mil dólares. Belterra ficou ligada ao Ministério da Agricultura que continuou desenvolvendo atividades de extração de borracha na região. De acordo com Sena (2008, p.96), "pelo decreto Lei 8.440 de 24 de dezembro de 1945, o Governo Federal estabeleceu normas para aquisição do acervo da CFIB, operação que se efetivou através do Banco de Credito da Amazônia S.A, atual Banco da Amazônia".

No final da década de 1950, Belterra passou a ser chamada de Estabelecimento Rural do Tapajós (ERT). Um montante de recurso público foi investido para manter o empreendimento e uma parte dos funcionários da CFIB transformados em servidores públicos federais, bem como outros continuaram sem vínculos empregatícios trabalhando de maneira precarizada, sobretudo, os que trabalhavam diretamente na extração do látex.

No período de 1946-1994, Belterra se apresenta em contexto de iniciativa de diversas esferas do governo para manter vivo o projeto, concepção de um corpo político administrativo, manutenção da infraestrutura, conservação de seringal, intensificação da comercialização do látex, criação de gado, produção de mudas de frutas e comercialização de madeira (PEREIRA, 2012).

Através da portaria Ministerial no 323, de 24/10/1980, o Ministério da Agricultura passou à jurisdição do INCRA parte das terras sem uso de Fordlândia e Belterra, para fins de regularização da posse da terra. Belterra passa a ser distrito de Santarém período em que surge o movimento para emancipação. Após a realização do plebiscito a lei 5.928/1995 criou o município de Belterra.

Podemos verificar que o Projeto de Ford foi o pioneiro em relação aos grandes investimentos na Amazônia, objetivando a exploração do potencial da floresta, trazendo consigo o discurso do desenvolvimento para a região. $\mathrm{O}$ pano de fundo em relação à vinda de Henry Ford para Amazônia situa-se no campo econômico e político. No que tange a questão econômica, a inserção do capital americano tinha pretensão de que os EUA tivessem como missão recriar o Éden capitalista na Amazônia (GRANDIN, 2010).

No final do século XX, mais um movimento do capital - a expansão do agronegócio - provoca disputas por terra entre os antigos seringueiros e os produtores de 
soja vindos de Santa Catarina, Rio Grande do Sul, Paraná e Mato Grosso. Esse contexto se apresenta em meio a uma série de conflitos socioambientais (PEREIRA, 2012).

O deslocamento do plantio de soja do centro oeste para o norte do país foi programado, resultado de um conjunto de estratégias organizadas pela articulação entre o Estado e o grande capital. Uma ação bastante planejada e seletiva que teve apoio político em diversos níveis, injeção de dinheiro público em vários casos, flexibilização da gestão ambiental, afrouxamento da fiscalização dos órgãos responsáveis e estudos científicos que auxiliaram a melhor localização do empreendimento (PEREIRA, 2012).

Conforme Pereira (2012), o contexto favorável que motivou o empreendimento foi o esgotamento das terras disponíveis no estado do Mato Grosso, provocada pelo plantio da soja em larga escala e pela abundância de terras às margens da Rodovia BR-163, no estado do Pará. Terras devolutas ou terras onde se localizavam os agricultores, advindos do projeto de colonização do INCRA na década de 1970 que pertenciam à população, principalmente a rural, de Santarém, Belterra e outros pertencentes aos municípios integrantes da região do baixo amazonas. O preço da terra tornou-se acessível aos produtores vindos de outras regiões. Adicionado a isso, os incentivos financeiros e políticos dos governos municipal, estadual e federal para oportunizar novos empreendimentos econômicos na região impulsionaram a abertura da nova fronteira agrícola.

De acordo com Shlesinger e Noronha (2006, p.74), "Santarém e Belterra fazem parte de uma das últimas fronteiras de reservas florestais do Pará, com unidades de conservação, como a Floresta Nacional do Tapajós e a Reserva Extrativista Tapajós Arapiuns". Esses espaços de conservação são de extrema importância para a economia das famílias que vivem nas áreas preservadas, e o avanço da cultura da soja ameaça este território.

A pavimentação da rodovia BR-163 figura entre os projetos estratégicos para a Amazônia desde o regime militar e foi reiterado pelo governo do então presidente Fernando Henrique Cardoso. As justificativas devem-se as possibilidades de ampliação do escoamento de grande parte da produção de grãos do centro-oeste, especialmente Mato Grosso, através do porto de Santarém. Localizado em uma área fluvial de fácil acesso ao Oceano Atlântico e por isso aos mercados da América do Norte e Europa, o porto de Santarém representa importante via de integração regional e nacional, o que também reduz os custos de transporte dos produtos, uma vez que é o porto mais próximo do destino da soja, quando comparado aos portos do sudeste do país (PEREIRA, 2012).

O mesmo argumento faz parte dos estudos realizados pela empresa multinacional Cargill como justificativa para a instalação de seu porto na orla da cidade de Santarém. Desta forma se apresenta a ótica da velha lógica da integração regional, uma ação articulada entre o Estado, produtores de soja do Mato Grosso, políticos e empresários de Santarém que constitui um campo fértil para deslanchar o empreendimento. Conhecidos na região como "sojeiros" ou "gaúchos", a maioria dos produtores de soja de Santarém e Belterra é natural do Centro Sul do país, tendo chegado à região a partir dos incentivos fiscais da própria prefeitura de Santarém que, em 1997, encomendou à EMBRAPA (Empresa Brasileira de Pesquisa Agropecuária) um estudo de zoneamento econômico agrícola (SHLESINGER e NORONHA, 2006).

Nesse contexto favorável que contribui para a intensificação do plantio de soja, os conflitos tornaram-se cada vez mais acirrados e se manifestaram das mais diferentes formas. De acordo com Pereira (2012, p. 137): 
Especulação imobiliária; inclusive com a venda ilegal de terras públicas por antigos mandatários de cargos públicos municipais; desmatamento de grandes áreas de florestas; extração ilegal de madeira; poluição de rios e igarapés por conta do uso de agrotóxico; ocupação por fazendeiros dos leitos de igarapés e de áreas públicas de uso comunitário e das comunidades ribeirinhas e de agricultores familiares.

Para viabilizar o projeto de novas modalidades produtivas foi necessário destruir ou desorganizar os modos de vidas dos agricultores de pequena propriedade no uso do trabalho de todos os integrantes da família, no trabalho não manual, na produção para alimentar as famílias ou na comercialização em pequena escala, especialmente no abastecimento das feiras das cidades, numa prática mais balanceada e menos predatória em relação à natureza e das relações sociais dos sujeitos envolvidas no contexto (PEREIRA, 2012).

Podemos verificar que a culminância dos conflitos sociais em Santarém e Belterra ocorreu no ano de 2006, quando as manifestações ganhararam notoriedade na cidade de Santarém e os campos de poder, pequenos agricultores, sociedade civil organizada, produtores de soja e ativistas passaram a se enfrentar abertamente através de passeata, manifestações públicas, cobertura da mídia e mobilizações que continham a defesa de ambas as partes, tal como o enfretamento entre a polícia e manifestantes em torno da empresa multinacional Cargill (PEREIRA, 2012).

Os produtores de soja foram recebidos por empresários, proprietários dos meios de comunicação, parte da classe política local e governo municipal como portadores do "progresso" e do "desenvolvimento". Cerca de 450 famílias de produtores de grãos já realizaram recentemente deslocamentos migratórios para Santarém e Belterra por conta dessas atividades produtivas. O conflito entre os produtores de soja (os recém-chegados vindos "de fora") e a população local (os antigos moradores do lugar) logo se desenvolveu entre ameaças e preconceitos. Mas no contexto da "fala do desenvolvimento" os Outsiders da Amazônia são indígenas, mestiços, agricultores, extrativistas, mulheres e trabalhadores urbanos que recebem do estranho vindo "de fora" adjetivos pejorativos de "preguiçosos", "pinguços" e são vistos como aqueles que representam o entrave para o progresso econômico (PEREIRA, 2012).

Os conflitos pela posse da terra envolvendo pequenos agricultores, empresários e produtores de soja, e as denúncias do desmatamento causado pela expansão da soja resultaram em ameaças feitas aos agricultores. Os principais lócus de conflitos são as localidades de Gleba Nova Olinda, Pacoval, Lago Grande, Jabuti, Tracuá, Garrafão, Igarapé das Pedras, Estrada de Curuá Una, entre outros (PEREIRA, 2012).

Segundo Pereira (2012) a situação foi mais complicada no início da década de 2000, pois compreende o assassinato do Agricultor José Orlando, em 2003, envolvendo madeireiros e policiais; expulsão de moradores de suas terras; e o incêndio de 25 casas, no ano de 2004 e 2005, nas quais as famílias residiam desde os anos de 1960. Há diversas ações como: grilagem de terra, extração ilegal de madeira e a regularização ilegal de terras.

De acordo com Pereira (2012), apresenta-se a ideia defendida acerca da soja como "cultura da morte", pois junto com ela vem a desunião das famílias, a degradação do meio ambiente e da biodiversidade. Muda o clima, diminui a produção de alimento (feijão, arroz, milho, e farinha de mandioca), a caça e a fruticultura (laranja, manga, cupuaçu, pupunha). Segundo o Sindicato dos Trabalhadores e Trabalhadoras Rurais de Santarém, entre os anos de 2005 e 2006, cerca de 500 famílias diziam-se arrependidas de terem vendido suas terras, pois acabaram migrando para a cidade de Santarém ou se 
estabeleceram em locais distantes de estradas e dos serviços públicos o que comprometeu a qualidade de vida. Reforçam essas afirmações Shlesinger e Noronha (2006, p.85):

\begin{abstract}
A expansão da soja nesses municípios pode estar ameaçando a segurança alimentar da população, pois vem ocorrendo um processo de queda do cultivo de produtos importantes na dieta alimentar, como feijão, milho e algumas frutas. Essa queda, bem acima da média estadual, regional e nacional, tem ocorrido no mesmo período em que o monocultivo da soja se expande nesses municípios.
\end{abstract}

A presença da multinacional Cargill no porto de Santarém constitui outro foco de tensão entre as partes envolvidas no conflito, já que a empresa se instalou na praia da Vera Paz em frente à cidade e que era de uso público. É importante ressaltar que essa praia era lugar de lazer da população santarena e região até final dos anos 1990, quando sem nenhuma consulta à comunidade, o governo do município repassou a área para a Cargill fazer a construção do porto para exportação de soja.

Pereira (2012) contextualiza que as noções de "desenvolvimento" e "progresso" são fortemente questionadas. Que tipo de desenvolvimento é este? Que concentra as terras nas mãos de poucos, que expulsa as famílias tradicionais de suas terras e os manda para a periferia da cidade, que poluí os rios e deixa as pessoas doentes com o intensivo uso de agrotóxico nas plantações de soja. Nesse caso, as disputas entre os de "dentro" e os de "fora" expressam algo mais do que quem é contra ou a favor da soja na Amazônia. A questão é sobre a concepção de desenvolvimento, seus benefícios e sobre como distribuir a riqueza produzida, muitas vezes sob a denominação de "desenvolvimento sustentável", o preço que tem sido pago pelo desenvolvimento é a destruição do povo da região, num processo desenfreado de expansão do capital.

\title{
Aspectos Geográficos e Econômicos: um breve panorama da cidade de Belterra
}

O município de Belterra está localizado na mesorregião do Baixo Amazonas, na microrregião de Santarém entre a rodovia BR-163 (Cuiabá-Santarém) e a margem direita do rio Tapajós. Apresenta uma população de 16.924 habitantes formada por indígenas, descendentes de indígenas, nordestinos, extrativistas, ribeirinhos e produtores de soja. Compreende uma área geográfica de 4.398,419 km², com uma densidade demográfica de $3,71 \mathrm{hab} / \mathrm{km}^{2}$. O Índice de Desenvolvimento Humano (IDH) é de 0,588 segundo o IBGE (2014).

Apresenta- se com característica predominantemente rural em sua organização espacial, uma vez que $58 \%$ da população vive no campo. Destaca-se que a vocação econômica do município está relacionada com a agricultura familiar, agricultura em larga escala (como a plantação de grãos de soja) e o agroextrativismo, distribuídos nas áreas de Planalto (BR-163) da Floresta Nacional do Tapajós- FLONA TAPAJÓS, Área de Proteção Ambiental Aramanaí- APA e área urbana municipal.

Na Floresta Nacional do Tapajós ${ }^{2}$ tem-se a exploração sustentável de recursos madeireiros. A população que habita a floresta é constituída de ribeirinhos que vivem do agroextrativismo e da agricultura de subsistência, cultivando mandioca, abóbora, feijão, café, banana, coleta de óleo de andiroba, óleo de copaíba, leite de seringa, mel de abelha, cumaru. Vivem também da pesca e da caça, além do artesanato. Nesta unidade de conservação estão localizadas as Terras indígenas de Bragança, Marituba e Taquara, onde vivem cerca de 400 habitantes indígenas denominados de Mundurukus. O município de Belterra, por meio da Lei no 097, de 30/05/2003, criou a Área de Proteção Ambiental Praia 
de Aramanaí, com uma área contígua que totaliza 10.985 ha, apresentando uma diversidade de plantas e florestas nativas. Está Área de Proteção Ambiental é formada por seis comunidades às margens do Rio Tapajós ${ }^{3}$. Nela residem pescadores, agricultores, barraqueiros que prestam serviços a visitantes e turistas.

Na área localizada no campo, denominada de Planalto (BR-163), está a população migrante do nordeste, sudeste e sul do país, provenientes dos projetos de colonização implementados pelo governo federal na década de 1970. Desenvolvem a plantação e comercialização de mandioca, grãos, pimenta do reino, legumes, frutas, verduras e criação de animais (bovinos, ovinos e aves). No planalto também residem os migrantes que chegaram por volta dos anos 2000 que são empresários do agronegócio.

A população urbana está localizada na área que foi no início do século XX sede do projeto Ford, e é composta de nativos que migram do campo para a área urbana, nordestinos, antigos empregados da empresa de Ford e seus filhos. A área localizada no meio rural detém $90 \%$ do território municipal, distribuída da seguinte forma: $70 \%$ da Floresta Nacional do Tapajós, 10\% da Área de Preservação Ambiental (APA) e 10\% da população que reside no eixo da BR-163.

De um lado possui uma população nativa que trabalha dentro de uma perspectiva da agricultura familiar, de outro, um grande grupo de empresários, produtores de soja que migraram do centro oeste e encontraram na região de Belterra o local apropriado para fazerem a plantação de grãos contando com o auxílio do governo, revelando um quadro preocupante de desigualdades e de negação de direitos sociais já antes vivenciado pela população local.

Nesse contexto, surge a necessidade de pensar uma escola que possa atender às demandas dos pequenos produtores e criar condições de manutenção da agricultura familiar diante da expansão do agronegócio na região.

\section{A criação da Escola Comunitária Casa Familiar Rural de Belterra}

Diante da ausência de uma política educacional voltada para os jovens do campo; da fragilização da agricultura familiar frente à ampliação da monocultura da soja e da carente rede educacional do município, organizou-se a luta pela criação da casa familiar de Belterra. Tal mobilização envolveu a reunião de produtores rurais, Sindicato dos Trabalhadores e Trabalhadoras Rurais, Movimentos Sociais, Associação das Casas Familiares Rurais - ARCAFAR regional e Governo Municipal.

O marco da criação da ECCFRB teve início no ano de 2009, quando cidadãos Belterrenses ligados aos movimentos sociais, especificamente em uma reunião dos conselhos dos fóruns dos movimentos sociais, discutiram as ações educacionais do município junto com a sociedade civil organizada. Esses sujeitos tinham conhecimento da existência da experiência da Pedagogia da Alternância na região da transamazônica e se organizaram para aprofundar os conhecimentos sobre a mesma.

Dessa reunião formou-se uma equipe de dez pessoas composta por lideranças de diferentes organizações. Deslocaram-se até a cidade de Altamira onde está sediada a ARCAFAR regional e iniciaram o processo de visitação a algumas escolas existentes, como as Casas Familiares Rurais de Altamira, Rurópolis, Medicilândia, Brasil Novo e Uruará, consolidando ainda mais o desejo de se criar uma Casa Familiar Rural em Belterra. Posteriormente, teve início o trabalho de envolvimento das comunidades de Belterra, com reuniões em diversas áreas do município e, especialmente, na comunidade do Prata, onde hoje está situada a ECCFRB, para sentir nas demais pessoas, e não só na opinião dos líderes, a possibilidade de ver instalada e funcionando uma ECCFRB no município. Houve 
ainda um trabalho junto aos fóruns de movimentos sociais, onde se discutia o processo de implantação para alunos que cursariam a formação Técnica em Agropecuária integrada ao ensino médio, principalmente por adotar o regime de Alternância uma vez que a população residia predominantemente no campo.

$\mathrm{O}$ trabalho de envolvimento das comunidades foi feito por uma equipe dentre as quais estava a atual presidente da Associação da Escola Comunitária Casa Familiar Rural de Belterra. Aconteceu uma primeira reunião na Comunidade do Prata para a discussão e reflexão sobre a criação da ECCFRB, bem como sua importância para a região. Logo em seguida foi chamada uma segunda reunião convidando as famílias trabalhadoras rurais, Movimento Social, o Sindicato dos Trabalhadores Rurais, famílias da região da Floresta Nacional do Tapajós e Governo Municipal. Esses atores sociais foram fundamentais no processo de criação da Casa Familiar Rural de Belterra. Na oportunidade, no dia 01 de agosto de 2010, aprovaram o estatuto da Associação da Casa Familiar Rural de Belterra, lembrando que a constituição da associação é pré-requisito para a organização da Casa Familiar rural, de acordo com a perspectiva do Centro de Formação por Alternância CEFFA.

Em 01 de agosto de 2010, criou-se a Associação da Casa Familiar Rural de Belterra, entidade mantenedora e cujos primeiros membros eleitos em Assembleia para mandatos de três anos, de acordo com os documentos, foram: Francisco Chagas (Presidente da Associação), Antônia Leal (Tesoureira), Marlene Sousa (Secretária) e José Julião de Sousa e José Renato Aragão (Conselho Fiscal). O período de duração do mandato foi de três anos.

O terreno documentado de 32 ha para construção da Escola foi doado por duas pessoas que integravam os movimentos sociais na década de 1980 na região de Belterra e Santarém: os Senhores Geraldo Pastana ${ }^{4}$ e Ranolfo Peloso. Ressalta-se que na área havia a construção uma pequena casa de madeira e uma escola ${ }^{5}$ construída pela prefeitura municipal de Santarém na frente do terreno. A mesma foi cedida em sistema de comodato ${ }^{6}$ para a Associação da Casa Familiar Rural de Belterra e está localizada na Comunidade do Prata, BR-163, a $32 \mathrm{~km}$ da sede do município.

Para compor as primeiras turmas foi aberto um edital para seleção dos alternantes. Foi feita uma divulgação nas comunidades e na cidade de Belterra. $\mathrm{O}$ objetivo era ofertar formação para filhos de trabalhadores rurais. Constava no edital a ficha de matrícula e a pesquisa de campo, esta última objetivava verificar se o jovem se identificava como filho de trabalhador rural. O trabalho desenvolvido teve orientação da ARCAFAR regional. Assim, cinquenta e oito jovens foram matriculados para compor o quadro dos alternantes nas primeiras turmas denominadas de Planalto16 e Tapajós ${ }^{7}$.

Segundo Youssef Filho (2013, p.133), “devido às diferenças culturais dessas duas regiões, a grade curricular teve que ser adaptada para atender os diferentes anseios de cada categoria". Foram realizadas duas assembleias extraordinárias que definiram o calendário das alternâncias, o Plano de Curso, incluindo os temas geradores e o Regimento Interno de Funcionamento da CFRB.

No dia 04 de abril de 2011, inaugurou-se a Casa Familiar Rural de Belterra, com programação iniciada com a concentração na própria Casa às 16:00 horas. Estavam presentes os alternantes; bem como seus familiares; os parceiros da experiência educacional; o prefeito de Belterra, Senhor Geraldo Pastana; Dilma Serrão ${ }^{8}$; Luís Rossi; e Irlanda Almeida, integrante do Movimento Social e uma das responsáveis pelo trabalho de base para implantação da CFRB. Na ocasião foi feito um chá de casa nova com objetivo de obter utensílios domésticos, bem como eletrodomésticos e eletrônicos para a CFRB. Destaca-se que mesmo tendo recebido apoio do poder público municipal a implantação da 
experiência já apresentava desde o início dificuldades de infraestrutura para atender às necessidades dos alternantes e monitores.

De acordo com o projeto político pedagógico (2010), a construção do currículo do ensino médio integrado à formação Técnica em Agropecuária ofertada aos alternantes das duas primeiras turmas aconteceu de maneira coletiva. Os temas geradores foram definidos a partir da realidade constatada na pesquisa das propriedades dos alternantes, após a sistematização foram ratificados em assembleia pela Associação da Casa Familiar Rural de Belterra com a participação dos alternantes, familiares, monitores e membros da associação.

No que tange a estrutura curricular da formação Técnica em Agropecuária Integrada ao Ensino Médio, buscou- se contribuições no IFPA (Instituto Federal do Pará), Escola Técnica de Castanhal e Orientações da ARCAFAR regional. É importante frisar que se recorreu ao IFPA e a Escola de Castanhal, por considerar a experiência que possuíam uma vez que também ofertavam o curso Técnico em Agropecuária Integrado ao Ensino Médio. A constituição deste currículo está fundamentada na Lei de Diretrizes e Bases da Educação 9394/96, com ênfase nas orientações para a educação do campo e o ensino profissionalizante e parâmetros curriculares para o Ensino Médio (PPP, 2010).

Ainda segundo o projeto político pedagógico (2010), na Casa Familiar Rural de Belterra, a educação estava comprometida com a luta pelo fortalecimento da produção familiar, com acesso às políticas públicas, tecnologia do trabalho, aprendizagem da gestão empreendedora, geração e renda e o enraizamento de uma nova cultura baseada na economia solidária. Ainda na CFRB, o ensino visava garantir o empoderamento social da juventude, por meio do acesso a tecnologias, conhecimentos e habilidades que possibilitem alcançar o nível técnico médio e a postura de cidadãos conscientes na profissão que estão inseridos.

$\mathrm{Na}$ orientação das duas primeiras turmas denominadas de Planalto e Tapajós a concepção de educação que está contida no Projeto Político Pedagógico está sob uma orientação Freireana e parte de uma perspectiva de educação libertadora. De acordo com o PPP (2010, p.08):

Somente o ser humano engajado nos movimentos sociais ou em projetos de interesse coletivo, independente de raça, religião, sexo, etc, adquire as condições para transformar o mundo e a sociedade em prol de conquistas fundamentais para mudar as regras e sistemas que fazem a sociedade ser desigual, injusta e opressora.

A concepção de educação proposta pela Casa Familiar Rural de Belterra afirma que nenhuma mudança é possível sem a educação. É necessário que os jovens agricultores da região de Belterra estejam engajados na luta pela sua libertação. Essa ação educativa seria capaz de libertar de toda e qualquer situação de opressão, tornando esse sujeito crítico e reflexivo. Este jovem, a partir dessa concepção de educação, discute e propõe mudanças na sua realidade, na sua escola e comunidade. Dessa forma a Casa Familiar Rural de Belterra poderia ser um lócus de engajamento da população do campo no enfrentamento das mazelas sociais, buscando sempre combater a dominação, exclusão, discriminação e submissão vigentes na sociedade capitalista.

O primeiros monitores que exerceram suas atividades na Casa Familiar Rural de Belterra foram: Luciano Gomes ${ }^{9}$, Dilma Serrão, Manoel Herculano Ferreira, Eraldo Moura, Zanildo Maranhão, Marlene de Castro, Mara Lúcia Furtado, Edson Moura, Werlisson Silva, Hudson Reis, Gabriel Buchale, Ednaura Silva e Conceição Almada. A primeira diretora que também respondia como coordenadora pedagógica foi a Senhora 
Antônia Pastana, que era esposa do prefeito e integrante de movimentos sociais. Além de duas cozinheiras as Senhoras Rita de Cássia Oliveira e Antônia Leal. Para serem contratados, os mesmos precisaram submeter currículo e fazer entrevistas.

A contratação aconteceu através da APRUBEF (Associação Dos Produtores Rurais de Boa Esperança e Fé Em Deus), que foi uma instituição parceira da CFR, uma vez que Associação da Casa Familiar Rural de Belterra não podia fazer a contratação, pois não preenchia o pré-requisito mínimo que era ter um ano de criação. Para custear as contratações, foi fechado o primeiro convênio com o governo do Estado do Pará através da Associação da Casa Familiar Rural de Belterra, além da parceria com a prefeitura municipal de Belterra. O convênio com o governo do Estado teve a duração de 01 ano, após a finalização, a prefeitura de Belterra passou a custear sozinha a contratação dos monitores, diretor, pedagogo e pessoal de apoio como cozinheiras e caseiros.

Além do convênio entre o governo do Estado do Pará e a prefeitura municipal de Belterra, podemos verificar outras parcerias estabelecidas com a CFRB para a implantação e execução da experiência educacional sob a perspectiva da alternância, tais como: EMATER (Empresa de Assistência Técnica e Extensão Rural), o escritório local contribuiu cedendo servidores técnicos para atuar como monitores de disciplinas de formação da área técnica; Secretarias de Cultura e de Meio Ambiente de Belterra; e FASE (Federação para Assistência Social e Educacional). Para auxiliar na logística das atividades o IPHAN (Instituto do Patrimônio Histórico e Artístico Nacional), COOMFLONA (Cooperativa Mista da FLONA Tapajós), STTR (Sindicato dos Trabalhadores e Trabalhadoras Rurais) de Belterra e Santarém cederam combustível e veículos para o transporte das equipes.

Em relação à certificação dos alunos, inicialmente o IFPA seria o órgão responsável por fazer a expedição dos certificados para os concluintes da formação em Técnico em Agropecuária Integrada ao Ensino Médio. No entanto, no ano de 2012 as Casa Familiares Rurais do Estado do Pará foram autorizadas a certificarem seus alunos através do Parecer n 398/2012 e Resolução no 457, de 20 de dezembro de 2012/ CEE-PARÁ. Ressalta-se que este foi um momento há muito aguardado pelas Casas do estado do Pará, uma vez que desde 1995 existia formação em alternância na região, no entanto o cenário em relação à certificação apresentava-se como uma das principais problemáticas, pois os alunos eram certificados através de escolas dos municípios onde as Casas estão localizadas, ou simplesmente os alternantes que recebiam formação não conseguiam ter acesso à certificação que oficializava a formação, seja em nível fundamental ou nível médio.

Vale ressaltar que a autorização da CFRB, bem como das outras Casas esteve em vigor até o ano de 2014, o que possibilitou a certificação das duas primeiras turmas, denominadas de Planalto e Tapajós. Em relação às atuais turmas de Belterra e Mojuí dos Campos, encontra-se em andamento junto à SEDUC (Secretaria Estadual de Educação) e ao CEE (Conselho Estadual de Educação) o processo de renovação de autorização para expedição da certificação dos alternantes.

Para finalizar as atividades das primeiras turmas que estavam recebendo formação na CFR de Belterra, a prefeitura de Mojuí dos Campos cedeu um pedagogo e um monitor da área técnica para auxiliar os alternantes na finalização do Primeiro Projeto de Vida do Jovem (PPVJ). Outros parceiros, como a Emater Santarém, Emater Regional, Emater de Mojuí dos Campos, Secretaria de Agricultura de Belterra, atuaram na composição da banca de defesa dos primeiros projetos de vida do jovem da CFR, além dos próprios monitores. A previsão para o encerramento era dezembro de 2013, entretanto a finalização aconteceu apenas em julho de 2014, seis meses depois, uma vez que houve um atraso considerável para a celebração do segundo convênio entre a Associação da ECCFRB e o governo do estado. 
Com relação à alimentação dos alternantes, no primeiro ano de funcionamento da Casa Familiar Rural, foi custeada pelo convênio com o governo do estado. Após a finalização do convênio, as famílias passaram a se responsabilizar pela alimentação dos alternantes, uma vez que a proposta educacional da pedagogia da alternância diz que alimentação é de responsabilidade das famílias. Após as famílias apresentarem dificuldades no fornecimento da alimentação, foi necessário recorrer à prefeitura municipal de Belterra para garantir alimento nas alternâncias, além da venda da produção da própria CFRB como: galinhas, ovos de galinhas, porcos e hortaliças. Segundo Youssef Filho (2013, p.135):

\begin{abstract}
A Casa Familiar Rural de Belterra também convive, além dos parcos recursos financeiros, com a carência de professores que não querem morar na zona rural, entre outras dificuldades. Não obstante, observou-se uma movimentação desses moradores para a superação dos problemas. São reuniões nas comunidades. Deslocam-se a Belterra e Santarém para solicitar apoio de diversas instituições. Formam comitivas para Belém e Brasília com o mesmo intuito. Diante disso, percebe-se o espírito de associativismo, a capacidade de articulação e mobilização desses moradores.
\end{abstract}

A contribuição mensal dos associados da Casa Familiar Rural de Belterra era de 2\% do Salário Mínimo, recolhida com o objetivo de custear o deslocamento para resolver questões burocráticas da Casa Familiar Rural de Belterra, bem como da Associação, o pagamento da energia, lembrando que nem todas as famílias podiam fazer a contribuição.

Com relação às duas primeiras turmas, foi possível perceber que dos 58 (cinquenta e oito) alunos matriculados que iniciaram suas atividades em 2011, 42 conseguiram finalizar a formação no ano de 2014. A média da idade dos alternantes era de 23 (vinte e três) anos. As duas turmas foram compostas com alternantes predominantemente do sexo masculino. Do total de cinquenta e oito alternantes apenas 17 (dezessete) eram do sexo feminino.

Destes, dois egressos conseguiram acessar o nível superior, uma jovem no curso de Pedagogia e um jovem no curso de Zootecnia na Universidade Federal do Oeste do Pará (UFOPA); uma egressa foi aprovada no concurso público no município de Belterra, mas não exerce atividade na área de sua formação; três egressos foram contratados por uma empresa e fazem extensão rural em assentamentos; dois egressos estão exercendo suas atividades na ECCFRB na condição de monitores; um egresso migrou para Santarém e montou seu próprio negócio que não é na área de formação; um egresso servindo às forças armadas; os demais continuam em suas comunidades trabalhando como agricultores.

Um problema enfrentado pelos egressos da Casa Familiar Rural de Belterra é com relação ao CREA (Conselho Regional de Engenharia e Agronomia), pois a documentação ainda se encontra em tramitação e os egressos encontram- se apenas com o certificado de conclusão, faltando a emissão da carteira que os credencia a exercer suas atividades de Técnico em Agropecuária.

\title{
Limites e possibilidades da implantação da experiência em alternância na ECCFRB
}

Santos (2006, p.345) pontua que "a maioria dos sujeitos, envolvidos no processo formativo em alternância, vislumbram uma escola diferente, voltada para o fortalecimento da agricultura familiar, à base de temas geradores emergidos da realidade cotidiana". A ECCFRB se propõe a trazer conteúdos associados à realidade do educando relacionando 
teoria e pratica, a partir dos temas geradores que são trabalhados em cada alternância, confrontando esses jovens com conhecimentos empíricos e conhecimentos científicos, o aprender acontece na prática do dia a dia, interligando os momentos na propriedade e períodos na escola. De acordo com Prazeres (2008, p.118):

\begin{abstract}
A articulação entre os conhecimentos de formação geral e técnica não são fáceis de serem materializados, uma vez que a educação, ao longo dos anos, segue na perspectiva de dicotomizar educação e trabalho, teoria e prática, escola e comunidade, conhecimentos científicos e saberes populares, a educação da vida dos sujeitos como se estes fossem algo apartado dos sujeitos e de sua realidade.
\end{abstract}

As relações entre teoria e prática se expressam em espaços distintos, o que sugere a reflexão a respeito de como as experiências educativas em alternância se organizam, relacionam-se e se amparam. Busca-se a concepção dos sujeitos das experiências em alternância, principalmente, na relação constituída entre a escola e ao espaço produtivo (SILVA, 2012).

De acordo com Zamberlan (1995, p.11), “é através da alternância que a sabedoria prática e a teórica se juntam. Ajuda a aprofundar coisas do dia a dia da família, comunidade e mundo geral. Ajuda a valorizar o trabalho do agricultor como forma de valorizar a cultura camponesa”.

As contribuições da ECCFRB para o fortalecimento das unidades produtivas da região perpassam por uma característica importante da pedagogia da alternância que é a relação teoria e prática no movimento de partida e chegada das informações representadas pelo tempo escola e tempo comunidade. É importante frisar que o fortalecimento das unidades produtivas está presente como objetivo no Plano de Formação da ECCFRB (2015, p. 6) "que é contribuir para a permanência do jovem agricultor e agricultora na sua atividade, fortalecendo o seu vínculo com a unidade de produção familiar e com sua localidade".

Santos (2006) concebe a importância de os conteúdos partirem das experiências do cotidiano das roças familiares e ainda pela interação entre as aulas teóricas e as práticas, possibilitando que os alunos tenham a vivência no laboratório das próprias roças. Com o domínio de técnicas relacionadas à agricultura, o alternante poderá potencializar a plantação/ e ou criação que ele possui no seu lote, contribuindo para o aumento do rendimento familiar, além da diversificação de produção nas propriedades. O jovem passa a ser inserido no processo de produção familiar com mais autonomia, tendo a possibilidade de acessar programas relacionados à agricultura familiar e com a formação técnica terá maiores chances de empreender sua própria produção.

O município em sua maioria é constituído por uma população, território e identidade rural, dessa forma a agricultura familiar fomenta a economia, melhorando e criando alternativas para a produção. Em entrevista o monitor Manoel ressaltou a fragilidade da economia do município onde as principais fontes de renda estão vinculadas aos empregos na prefeitura e a produção dos pequenos produtores da região. Pontua que uma das grandes contribuições da ECCFRB para a região é a formação técnica aos jovens, criando oportunidade de trabalho em suas comunidades e a sensibilização quanto à questão ambiental.

Considera que a ECCFRB como uma forma de resistência, visto o grande avanço do agronegócio na região. De acordo com Manoel, a Casa Familiar é "uma resistência ao agronegócio, uma alternativa que está dando certo, contrapondo a questão do agronegócio que está invadindo nossa região, em principal a região de Santarém, Mojuí dos Campos e 
Belterra". A ECCFRB fomenta através da formação técnica dos jovens agricultores o fortalecimento da agricultura familiar nas comunidades que ainda não desapareceram.

De acordo com Youssef Filho (2013, p. 134), "a implantação da experiência educacional não foi por acaso. Tem como objetivo estimular a revitalização desse povoado que está prestes a se afogar, envolto a plantações de soja e milho". A comunidade do Prata, onde está localizada a ECCFRB é percebida pelos moradores da região como o símbolo da resistência, pois foi nesse espaço que se originou as primeiras contestações sobre as condições precárias vividas pelos pequenos agricultores, nascendo várias associações de trabalhadores rurais que se espalharam por toda a região de Santarém.

Manoel acredita que o fortalecimento das unidades produtivas influencia para a permanência do homem no campo. Mas para que isso aconteça, ele menciona uma condicionante, para ele é necessário fortalecer o debate em relação ao acesso a políticas públicas para a agricultura familiar. É indispensável que o agricultor tenha incentivo de cooperativas, sindicatos e associações como parceiros. O monitor também cita programas como o PNAE (programa nacional de alimentação escolar) e PAA (plano de aquisição de alimentos) que estão relacionados com o mercado de fruticultura que podem garantir renda para os agricultores.

Ainda pode influenciar nessa permanência o acesso ao crédito rural como o PRONAFE JOVEM, que também pode ser acessado pelos jovens agricultores. Esse crédito auxilia na produção das culturas dos lotes. Para oferecer condições de permanência do jovem no campo é necessário criar e fortalecer as redes de parcerias existentes. Na concepção de Manoel, é preciso que se incentive a permanência do jovem na zona rural, no entanto, se essa permanência acontecer de maneira isolada, sem as condições necessárias, pode aumentar o êxodo rural. Esse jovem pode ser absorvido pelo agronegócio como uma mão de obra qualificada e barata. De acordo com Bezerra Neto (2003, p.211):

Evidencia-se, portanto que, as condições objetivas de fixação do trabalhador rural no campo dependem de medidas econômicas que favoreçam a sua permanência na roça e não de pedagogias impostas em determinados momentos ou dos esforços despendidos por meio da educação. São as condições reais de sobrevivência, ligadas a maneiras como os trabalhadores rurais se organizam, para produzir sua existência, que determinam suas formas de vida e não as ideias produzidas pelo homem de um dado habitat.

O autor menciona que a educação sozinha não fixa o homem no campo. A esta não pode ser atribuída à missão de ser a redentora das questões relacionadas à população do campo, a educação proposta de maneira isolada não consegue fazer as mudanças necessárias para melhorar as condições dos sujeitos. Essa transformação deverá estar ligada às questões econômicas, estruturais e sociais vigentes.

\section{Algumas considerações}

A investigação permitiu registrar o histórico da criação da ECCFRB que se deu a partir da luta e da organização dos movimentos sociais locais como estratégia para enfrentar o êxodo rural, o avanço do agronegócio e da monocultura de soja e as carências educacionais do município de Belterra.

Percebeu-se que o fortalecimento das unidades produtivas tem influência para a permanência do homem no campo. No entanto, é importante observar que em um contexto de expansão capitalista é necessário fortalecer o debate em relação ao acesso a políticas 
públicas para a agricultura familiar de modo que esta permanência se dê de modo a resgatar os valores de dignidade de vida dos sujeitos. Destaca-se ainda que a experiência educacional proposta na ECCFRB apresenta elementos críticos e de enfrentamento das problemáticas acima anunciadas, mas tem que se ter a compreensão de que a educação sozinha não fixa o homem no campo. A esta não pode ser atribuída a missão de ser a redentora das problemáticas relacionadas à população do campo uma vez que a educação proposta de maneira isolada não consegue fazer as mudanças necessárias para melhorar as condições dos sujeitos (BEZERRA NETO, 2003).

Foi possível verificar ainda que houve avanços no processo educacional dos sujeitos envolvidos na experiência, no entanto, há ainda muitos desafios a serem enfrentados. Em que pese as dificuldades vivenciadas pelo coletivo da escola esta experiência se apresenta como uma possibilidade de educação para o campo, todavia, deve ser problematizada e refletida pelos sujeitos que compõem o espaço escolar e deverão ser criadas pelo poder público melhores condições materiais para seu funcionamento.

\section{Referências:}

ASSOCIAÇÃO DAS FAMÍLIAS DA CASA FAMILIAR RURAL NO MUNICIPIO DE BELTERRA. Regimento Interno da Escola Comunitária Casa Familiar Rural de Belterra. Belterra, PA. 2015.

ARCAFAR/PARÁ. Regimento Escolar Unificado das Escolas Comunitárias do Estado do Pará. Altamira, PA, 2012. Digitado

ARAÚJO, Sandra Regina Magalhães de. Escola para o trabalho, escola para a vida: o caso da Escola Família Agrícola de Angical - Bahia. 2005. 219f. Dissertação (Mestrado em Educação e Contemporaneidade) - UNEB/BA, Salvador, 2005.

BEZERRA NETO, Luiz. Avanços e retrocessos da educação rural no Brasil. 2003. 221f. Tese (Doutorado em Educação) - Universidade Estadual de Campinas, Faculdade de Educação, Campinas, 2003.

BRASIL/ MEC. Referências para uma Política Nacional do Campo. Cadernos de Subsídios. Brasília: Secretaria de Educação Continuada, Alfabetização e Diversidade/Grupo Permanente de Trabalho de Educação do Campo, 2005.

BRAYNER, Conceição de Nazaré de Morais. Sistema de Organização Modular de Ensino: um estudo avaliativo da organização do trabalho pedagógico no ensino médio do meio rural. Belém, 2012. Dissertação (Mestrado em Educação) - Universidade do Estado do Pará - UEPA. (137 f).

CASA FAMiliar RURAL DE BELTERRA. Projeto Político Pedagógico. 2010.

CASA FAMILIAR RURAL DE BELTERRA. Ata da Assembleia geral ordinária de eleição e posse da nova diretoria e do conselho fiscal da Associação das Famílias da Casa Familiar Rural de Belterra. Belterra, PA, 2013. Digitado 
ESCOLA COMUNitÁRIA CASA FAMILIAR RURAL DE BELTERRA. Plano de Formação. Belterra, PA. 2015.

FREIRE, Paulo. Pedagogia do Oprimido. São Paulo: Paz e Terra, 2005.

GIMONET, Jean Claude; Praticar e compreender a Pedagogia da Alternância dos CEFFAS. tradução de Thierry de Burghgrave. Petrópolis, RJ: Vozes, 2007.

GRANDIN, Greg. Fordlândia: ascensão e queda da cidade esquecida de Henry Ford na selva. Rio de Janeiro: Rocco, 2010.

IBGE. Censo Demográfico 2014. Disponível em: www.cidades.ibge.gov.br Acessado em 01/06/2015.

PEREIRA, José Carlos Matos. Os modos de vida na cidade: Belterra, um estudo de caso na Amazônia Brasileira. Tese de Doutorado. Universidade do Estado do Rio de Janeiro, 2012. $256 \mathrm{f}$.

PRAZERES. Maria Sueli Corrêa dos. Educação no campo e participação social: reflexões sobre a experiência da Casa Familiar Rural de Cametál PA. Dissertação (Mestrado em Educação)-Universidade Federal do Pará, 2008. 191 f.

SANTOS, Neila Reis. Educação no Campo e alternância: reflexões sobre uma experiência na transamazônica/Pará. Tese de Doutorado em Educação. Universidade Federal do Rio Grande do Norte, 2006. 401f.

SHLESINGER, Sérgio; NORONHA, Sílvia. O Brasil está nu: o avanço da monocultura da soja, o grão que cresceu demais. Rio de Janeiro: FASE, 2006.

SENA, Cristovam. Fordlândia: breve relato sobre a presença americana na Amazônia. In: História, ciência e fronteira na Amazônia. São Paulo: Instituto Butantã. Cadernos de histórias das ciências. v. 4.n.2, p.90-107, jul./dez.2008.

SILVA, Lourdes Helena da. Experiências de formação de jovens do campo: alternância ou alternâncias? Curitiba, PR: CRV, 2012.

YOUSSEF FILHO, Adnan Assad. Comunidades persistentes: a resistência dos moradores da região de Açaizal do Prata. Dissertação de Mestrado, Programa de Antropologia. Universidade Federal de Pernambuco. Recife: 2013. 166 f.

ZAMBERLAN, Sérgio. Pedagogia da Alternância: escola da família agrícola. Santa Tereza, ES: MEPES, 1995.

Notas

\footnotetext{
${ }^{1}$ Em 1878, o inglês Henry Alexander Wilkham, a serviço do Royal Botanical Garden em Londres, coletou e enviou para a Inglaterra cerca de 70 mil sementes de (Hevea brasilienses), originárias da região de Boim, no
} 
vale Tapajós. As sementes foram plantadas em colônias britânicas na Malásia que deu origem a extensos seringais de cultivo com alta produtividade de borracha por hectare. Em cerca de cinquenta anos os ingleses desbancaram a Amazônia e se tornaram um dos maiores produtores de borracha no mundo, causando um grande desastre econômico na região (SENA, 2008, p.91).

${ }^{2}$ A Floresta Nacional do Tapajós foi criada pelo Decreto no. 73.684 de 19 de fevereiro de 1974. A segunda Floresta Nacional criada na região Norte e a segunda no Estado do Pará, abrange os municípios de: Aveiro, Belterra, Placas e Rurópolis.

${ }^{3}$ Comunidade de Pindobal, Porto Novo, Aramanaí, Cajutuba, Iruçanga, Santa Cruz e parte da comunidade de São Domingos.

${ }^{4} \mathrm{Na}$ época da Constituição da Associação e da Casa Familiar Rural de Belterra o mesmo era prefeito do Município de Belterra, por dois mandatos consecutivos, entre os anos de 2005 a 2008 no primeiro mandato e de 2009 a 2011 em seu segundo mandato, pelo Partido dos Trabalhadores.

5 Chamava-se Escola Municipal São Francisco, foi fechada por falta de alunos, devido ao êxodo rural na região de Belterra na década de 1990, onde havia um total de 49 famílias, apenas 06 seis resistiram e não venderam suas terras (PPP, 2010, p. 03).

${ }^{6}$ Comodato tem previsão no Código Civil Brasileiro (Lei n. ${ }^{\circ} 10.406$ de 10 de janeiro de 2002) em seus artigos 579 a 585 e é o contrato unilateral, gratuito, pelo qual alguém (comodante) entrega a outrem (comodatário) coisa infungível, para ser usada temporariamente e depois restituída. Uma vez que a coisa é infungível, gera para o comodatário a obrigação de restituir um corpo certo.

${ }^{7}$ Comunidades da região do Planalto em Belterra que tinham alternantes matriculados na Casa Familiar Rural eram: Renascer, São Franscisco do Km 119, São Raimundo do Fé em Deus, Açaizal do Prata, Igarapé Seco, Jabuti, São Benedito, Chaves e Acampamento. Nessa região foram beneficiados 29 jovens, filhos de pequenos agricultores da região.

${ }^{8} \mathrm{Na}$ época da inauguração da Casa Familiar Rural de Belterra a mesma era Secretária de Educação do Município de Belterra. Hoje é atual prefeita pelo Partido dos Trabalhadores.

${ }^{9}$ Atual Secretário de Educação do município de Belterra.

Recebido: dezembro-15 Aprovado: janeiro-16 